\title{
On the Issues of a "Corresponding Author" Field-Based Monitoring Approach for Gold Open Access Publications and Derivative Cost Calculations
}

\author{
Christian Gumpenberger*, Lothar Hölbling and Juan Ignacio Gorraiz \\ Department for Bibliometrics and Publication Strategies, Library and Archive Services, University of Vienna, Vienna, Austria
}

Keywords: open access publishing, Gold Open Access, article processing charges, transformation, corresponding author, monitoring, cost calculation

Within the last decade, the open access movement has gained momentum (Joseph, 2013), and researchers, research funders, and publishers find themselves confronted with challenges of all different kinds and dimensions. One of the major challenges is definitely cost-related. How can the outdated traditional subscription-based publishing model be successfully transformed into a sustainable open access model, which pleases all involved stakeholders alike? Currently, the research community, including research administrators, funders, and libraries has to deal with a colorful mix of models ranging from closed subscription to hybrid access to open access in different forms (Kaier and Ginther, 2017). Despite the importance and value of Green Open Access and repositories,

OPEN ACCESS

Edited by:

Xianwen Wang,

Dalian University of Technology

(DUT), China

Reviewed by:

Victor Herrero-Solana,

University of Granada, Spain

Marc Bertin,

Claude Bernard University Lyon 1,

France

*Correspondence:

Christian Gumpenberger

christian.gumpenberger@univie.ac.at

Received: 24 November 2017

Accepted: 15 January 2018

Published: 05 February 2018

Citation:

Gumpenberger C, Hölbling $L$ and Gorraiz Jl (2018) On the Issues of a "Corresponding Author" Field-Based Monitoring Approach for Gold Open Access Publications and Derivative Cost Calculations.

Front. Res. Metr. Anal. 3:1. doi: 10.3389/frma.2018.00001 particularly Gold Open Access is currently tackled as the apparently most promising route to achieve the anticipated transformation finally (Pinfield et al., 2017).

Therefore, many initiatives around the globe rather focus on Gold Open Access, which economics not exclusively but heavily rely on so-called article processing charges (APCs). The same principle applies to hybrid access (Björk, 2017), whenever an article is made open access in a traditional journal by the authors' request. As a result of the current co-existence of subscription fees and APCs during this transformation period, the unloved phenomenon of "double dipping" (payment for both subscription and open access fees) put the publishers on the spot. Due to this unstoppable development with a growing number of government and funding agency mandates and ever decreasing library budgets, the publishers have started to acknowledge the signs of the times and the need to adapt (Laakso et al., 2016). Major publishers such as Springer, Emerald, Sage, Taylor \& Francis, IOP, and RSC have already agreed to either "offsetting" (APCs are bundled with subscription licenses) or "read and publish" (affiliated authors can access all licensed journals and also publish OA without extra cost) deals (Earney, 2017; Holzer, 2017). Universities, research societies, or even countries can now benefit from these new arrangements.

In the long run, the subscription model is doomed. To speed up this evolutionary process, it is inevitable to come up with the estimated costs for this transformation (Schimmer et al., 2015). National and international initiatives aim to shed some light on this crucial information.

Such an initiative, called "Austrian Transition to Open Access-AT2OA", has just recently started in Austria. It is promoted by the Federal Ministry of Science, Research and Economy (BMWFW) and involves 21 Austrian universities under the lead of the University of Vienna. According to its project title, the aim is to foster the transformation from closed to open access of scholarly publications. One subproject will explicitly address potential impacts of this anticipated transformation. Within

${ }^{1}$ http://at2oa.at/ueber.html. 
the scope of this subproject, a bibliometric analysis was commissioned to determine all Austrian Gold Open Access publications retrieved in Web of Science and Scopus for the last three publication years. The obtained results will inform cost estimation models for the nationwide transformation.

The retrieval of all Austrian publications in Gold Open Access journals relies on two indexed fields in the before mentioned bibliographic databases: first, the Open Access status of the publication; second, a corresponding author affiliated to an Austrian institution (because usually the APCs are paid by the corresponding author's affiliated institution ${ }^{2}$ ) (Machado et al., 2016).

In spite of the fact that AT2OA has hardly been launched and the mentioned bibliometric analysis is still ongoing, it has already become very clear that any Gold Open Access monitoring approach based on the "corresponding author" field is far from ideal.

Depending on the discipline, the corresponding author can be the major contributor, a senior researcher, or simply someone with a stable email address chosen to take this role. Ideally, it is one single person who handles the whole manuscript and correspondence with the publisher during the publication process from submission to acceptance. The corresponding author would also remain the point of contact for any post-publication inquiries.

The rapidly changing world of open access publishing has further complicated the role of the corresponding author, who is now usually associated with the institution or funder that paid for the publication. This new practice has certainly reshaped the area of responsibility of the corresponding author. In addition to the previously mentioned traditional functions, he or she is now also in charge of assuring the publication costs. Due to these extended responsibilities, multiple corresponding authors for a single publication are more and more common, who mutually share different competencies. A development that is particularly true for interdisciplinary research.

Based on our observation we have identified following two major issues:

1. Many identified corresponding authors have more than one affiliation. So which is the paying one?

\footnotetext{
${ }^{2}$ Unfortunately, the "funding fields" in databases are hardly revelatory concerning open access publishing payment details. The "funding fields" are either empty or the information provided is rather general in concern of the overall funding, but without the necessary clarification regarding who actually covers the APCs.
}

\section{REFERENCES}

Björk, B.-C. (2017). Growth of hybrid open access, 2009-2016. PeerJ 5, e3878. doi: $10.7717 /$ peerj. 3878

Earney, L. (2017). Offsetting and its discontents: challenges and opportunities of open access offsetting agreements. UKSG Insights 30, 11-24. doi:10.1629/ uksg. 345

Holzer, A. (2017). Wozu open-access-transformationsverträge? o-bib. Das offene Bibliotheksjournal, Bd. 4, Nr. 2. doi:10.5282/o-bib/2017H2S87-95

Joseph, H. (2013). The open access movement grows up: taking stock of a revolution. PLoS Biol. 11:e1001686. doi:10.1371/journal.pbio.1001686

Kaier, C., and Ginther, C. (2017). Gold Open Access and Hybrid Open Access Wege zur Transformation, Stakeholder, Herausforderungen. Bibliotheksdienst 51, 991-1008. doi:10.1515/bd-2017-0115
2. Some publications have more than one corresponding author. Again, who pays?

Consequently, these issues have a somewhat negative effect on the accuracy of the obtained monitoring results. Moreover, it is noteworthy that not all agreements with publishers explicitly put the corresponding author in charge for the open access payment. For some institutions (e.g., ETH Zurich ${ }^{3}$ ), either the first or the corresponding author can take this role.

Since monitoring exercises are very likely to expand internationally, it is probably wise to reconsider the current approach based on the "corresponding author" field, before more complex workflows and processes become established. Alternatively, a field such as "OA paying affiliation" could be introduced in databases such as Web of Science and Scopus, in current research information systems, in repositories and of course in all journal submission systems. By doing so, affiliated authors could be flagged with a $\$$ \$ symbol or some equivalent. If the open access payment information was uncoupled from the "corresponding author" field, it would not only facilitate more accurate monitoring but would also prevent authors affiliated to the wealthiest institution, respectively, endowed with the most substantial funding being forced into the corresponding author role. Moreover, this would also allow unambiguous monitoring of multiple "OA paying affiliations" per publication. Even if this is not a current payment modality due to its complexity, it is not set in stone that publications will not have multiple funders in the future. Being aware of this possibility cannot be wrong.

To conclude, all open access monitoring exercises are still in their infancy. Therefore, methodological shortcomings should be addressed right in the start. The "corresponding author" field approach might be such a shortcoming.

\section{AUTHOR CONTRIBUTIONS}

JG developed the idea for this opinion piece, and all three authors contributed equally to its conception. CG performed the literature search and drafted the manuscript. JG and LH provided critical revisions.

${ }^{3}$ http://www.library.ethz.ch/ms/Open-Access-an-der-ETH-Zuerich/Publizierenin-Open-Access-Zeitschriften/Publizieren-in-Open-Access-ZeitschriftenFinanzierung.

Laakso, M., Solomon, D., and Björk, B.-C. (2016). How subscription-based scholarly journals can convert to open access: a review of approaches: converting journals to open access. Learn. Publ. 29, 259-269. doi:10.1002/ leap. 1056

Machado, A., Hoppmann, L., Knaus, J., and Palzenberger, M. (2016). Analysis of the international journal publishing activities in Switzerland with special emphasis on gold open access publishing. doi:10.5281/zenodo. 167381

Pinfield, S., Salter, J., and Bath, P. A. (2017). A "gold-centric" implementation of open access: hybrid journals, the "total cost of publication," and policy development in the UK and beyond. J. Assoc. Inf. Sci. Technol. 68, 2248-2263. doi:10.1002/ asi. 23742

Schimmer, R., Geschuhn, K. K., and Vogler, A. (2015). "Disrupting the subscription journals' business model for the necessary large-scale transformation to 
open access," in Max Planck Digital Library Open Access Policy White Paper (MPG.PuRe). Available at: http://hdl.handle.net/11858/00-001M-0000-0026C274-7

Conflict of Interest Statement: The authors declare that the research was conducted in the absence of any commercial or financial relationships that could be construed as a potential conflict of interest.
Copyright (๑) 2018 Gumpenberger, Hölbling and Gorraiz. This is an open-access article distributed under the terms of the Creative Commons Attribution License (CC BY). The use, distribution or reproduction in other forums is permitted, provided the original author(s) and the copyright owner are credited and that the original publication in this journal is cited, in accordance with accepted academic practice. No use, distribution or reproduction is permitted which does not comply with these terms. 